\title{
A RECAPITULATION OF THE GENETICS AND EVOLUTION OF INSECT BIOTYPES ON CEREALS: THE CASE STUDY OF THE HESSIAN FLY
}

\author{
C. KUDAGAMAGE, J.E. FOSTER AND J.E. ARAYA* \\ Department of Entomology, Purdue University, West Lafayette, IN 47907
}

(Date of receipt : 16 June 1987)

(Date of acceptance : 25 August 1987)

\begin{abstract}
The host-specific nature of the Hessian fly, Mayetiola destructor (Say) and its genetic interaction with the wheat (Triticum aestivum L. em. Thell) plant results in the evolution of virulent biotypes. However, carefully planned deployment of resistant genes can delay the evolution of biotypes and maximize the stability of resistant genes. The usefulness of the Hessian fly-wheat interaction model in breeding for insect resistance in rice is discussed.
\end{abstract}

\section{Introduction}

\subsection{Biotype Concept}

The importance of resistant cultivars for use in integrated control strategies of agricultural insect pests has served to emphasize the need for a basic understanding of the variation in the response of resistant crop cultivars. Some insect pests have increased their virulence and cause significant damage to cultivars which previously showed resistance. Such apparently new forms of pests have been termed host races or biotypes. In the glossary to their compendium on breeding plants resistant to insects, Maxwell and Jennings 25 define the term biotype in entomology as 'an individual or a population that is distinguished from the rest of its species by criteria other than morphology; for example, a difference in parasitic ability.'

The terminology employed to describe the genetic and environmentally induced phenotypic variation in phytophagous insects is extensive and include such terms as race (geographic and host race), biotype, ecotype, pathotype, form, morph, strain, variety, subspecies, semispecies, etc. ${ }^{9}$ The term biotype is more specifically used for individuals and populations of species which share certain biological characteristics usually concerning virulence on specific host cultivars. The term is more appropriate when genes or genotypes for virulence in a pest are known to correspond with particular genes for resistance in a host plant. ${ }^{5}$ This type of interaction has not been demonstrated in all insects where biotypes have been described. The best

* Graduate Research Assistant, Research Entomologist and Research Leader of the Insects and Weed Control Research Unit, USDA-ARS and also.Adjunct Professor, and Research Associate, respectively, in Dept. of Entomology, Purdue University, W. Lafayette, IN 47907, U.S.A. 
understood case of genetic-interrelationship between virulent genes in the insect and resistant genes in the plant is that of the Hessian fly-wheat interaction. Therefore, this system stands as a model for cereal insect-plant studies. Resistant rice cultivars play a major role in the management of rice insects but their longterm stability is threatened because of the evolution of biotypes. The knowledge available on the Hessian fly-wheat interaction could be used in rice insect host-plant resistance studies.

\subsection{Objectives}

This paper reviews the mechanisms involved in the development of biotypes of Hessian fly on wheat and the strategies used by plant breeders to manage the plant resistance to control Hessian fly biotype development. Also, the usefulness of some of these strategies in breeding for insect resistance in rice will be discussed.

\section{Genetics of resistance in wheat to Hessian fly}

The Hessian fly, Mayetiola destructor (Say), is a significant pest of wheat in the midwest and other wheat producing regions of the United States. ${ }^{12}$ Emphasis has been placed on using resistant wheat cultivars to limit the damage caused by this pest. Sixteen wheat genes for resistance to Hessian fly have been identified to the present time (Table 1). Many of these have been incorporated in to high yielding wheat cultivars and are widely grown in the field. The wheat chromosomes carrying some of these genes for resistance have been determined using monosomic analysis. For example, Gallun and Patterson ${ }^{16}$ found the $\mathrm{H}_{6}$ gene, derived from PI 94587 durum wheat (Triticum turgidum var. durum), located on chromosome 5A. Subsequent linkage studies by Patterson and Gallun ${ }^{32}$ and Stebbins et al. ${ }^{38}$ located the genes $\mathrm{H}_{3}, \mathrm{H}_{6}, \mathrm{H}_{9}$ and $\mathrm{H}_{10}$ all on chromosome $5 \mathrm{~A}$. The $\mathrm{H}_{5}$ gene has been shown to be independent of the $\mathrm{H}_{3}$ gene and linked to the $\mathrm{H}_{11}$ gene ${ }^{29}$. Also using monosomic analysis, Roberts and Gallun ${ }^{34}$ located the $\mathrm{H}_{5}$ gene on chromosome 1A. The $\mathrm{H}_{13}$ gene was derived from Triticum tauschii (Coss.); hence the resistance it provides is different from other types of resistance. This gene is presumably associated with the $\mathrm{D}$ genome of the wheat plant and is on chromosome $6 \mathrm{D} .17,20$

The location of resistant genes on specific chromosomes is important in genetic engineering research and also in studies of evolution of the virulence of Hessian fly biotypes. 
Table 1. Various wheat genes identified as having resistance to the Hessian fly, Mayetiola destructor (Say)

\begin{tabular}{|c|c|c|c|}
\hline $\begin{array}{l}\text { Resistant } \\
\text { Genes }\end{array}$ & $\begin{array}{l}\text { Nature of } \\
\text { resistance }\end{array}$ & $\begin{array}{l}\text { Sources of resistance } \\
\text { (cultivars) }\end{array}$ & $\begin{array}{l}\text { Reference } \\
\text { No. }\end{array}$ \\
\hline $\mathrm{H}_{1} \mathrm{H}_{2}$ & $\begin{array}{l}\text { Complementary } \\
\text { dominant }\end{array}$ & 'Dawson' & 28 \\
\hline $\mathrm{H}_{3}$ & Dominant & 'W38' & 4 \\
\hline $\mathrm{h}_{4}$ & Recessive & 'Java' & 39 \\
\hline $\mathrm{H}_{5}$ & Dominant & 'Ribeiro' & 36 \\
\hline $\mathrm{H}_{6}$ & Dominant & $\begin{array}{l}\text { P.1.94586 } \\
\text { (diploid durum) }\end{array}$ & 1 \\
\hline $\mathrm{H}_{7} \mathrm{H}_{8}$ & Partially dominant & 'Seneca' & 31 \\
\hline $\mathrm{H}_{9} \mathrm{H}_{10}$ & $\begin{array}{l}\text { Independent } \\
\text { dominant }\end{array}$ & $\begin{array}{l}\text { 'Elva' (tetraploid) } \\
\text { (Triticum turgidum) }\end{array}$ & 38 \\
\hline $\mathrm{H}_{11}$ & Dominant (tetraploid) & P.I. 94587 & 38 \\
\hline $\mathrm{H}_{12}$ & Dominant & 'Luso' & 29 \\
\hline $\mathrm{H}_{13}$ & Dominant & $\begin{array}{l}\text { Triticum tauscbii } \\
\text { (D- genome) }\end{array}$ & 20 \\
\hline $\mathrm{H}_{14} \mathrm{H}_{15}$ & $\begin{array}{l}\text { Independent } \\
\text { dominant }\end{array}$ & $\begin{array}{l}\text { 'ELS 6404-160' } \\
\text { (diploid durum) }\end{array}$ & 23 \\
\hline $\mathrm{H}_{16}$ & Dominant & $\begin{array}{l}\text { PI } 94587 \\
\text { (diploid durum) }\end{array}$ & 30 \\
\hline
\end{tabular}

\section{Hessian fly biotypes}

\subsection{Occurrence of Hessian fly biotypes}

Since there are sixteen genes for resistance identified in wheat, there are potentially $2^{16}$ or 65,536 possible Hessian fly biotypes, assuming each biotype differs in at least one gene specifically matching one of the host's 16 resistant genes. However, only a small fraction of this potential diversity has been directly assayed. In most experiments only four resistant wheat varieties have been utilized, each having a different resistant gene or gene pair. Using these four differential resistant varieties to assess the fly's genotype, there is a total of 16 possible biotypes. ${ }^{12}$ To date, 12 biotypes have been identified. $^{12,21,37}$

\subsection{Identification of biotypes}

When Hessian fly larvae feed on a susceptible wheat plant, the leaves become stunted and dark green, and the new leaves fail to form. Resistant seedlings 
show initially some leaf stunting, but they recover and remain light-green as do non-infested plants. Larvae that feed on resistant plants usually die. Thus, the virulent larvae can be distinguished from avirulent larvae by the reaction of the plant to the infestation. Biotype designation is based on the virulence or avirulence of larvae to specific wheat cultivars having known genes for resistance. One biotype may be virulent on a specific cultivar, while another may be avirulent. Virulence and avirulence are thus terms describing the insect's reaction to the host plant, whereas resistance and susceptibility are terms describing the plant's reaction to the insect. The phenotype of any biotype can be determined by scoring the reaction of four wheat differentials having five genes $\left(\mathrm{H}_{3}, \mathrm{H}_{7} \mathrm{H}_{8}, \mathrm{H}_{6}\right.$ and $\left.\mathrm{H}_{5}\right)$ to larvae of the same progenitor and the ability or inability of the larvae to survive. Wheat seedlings of known genotypes are grown and infested by a gravid female which lays eggs at random on the plants, without showing any host preference. The reaction of the seedlings is observed 15 days after infestation. The seedling reaction indicates the phenotype of the progeny.

The Great Plains (GP) biotype is the least virulent of the biotypes and it cannot attack wheat cultivars with the $\mathrm{H}_{3}, \mathrm{H}_{7} \mathrm{H}_{8}, \mathrm{H}_{6}$ and $\mathrm{H}_{5}$ genes. This biotype can only live on wheats having no known resistant genes and it was probably the first biotype that entered the United States 200 years ago. ${ }^{12}$ The most virulent biotype is designated as $\mathrm{L}$, which is capable of attacking all four differentials used. However, newer genes such as $\mathrm{H}_{9}$ and $\mathrm{H}_{13}$, are resistant to this biotype.

\subsection{The gene-for-gene concept}

Hybridization experiments with Hessian fly biotypes have provided evidence for a gene-for-gene interaction between the fly and its wheat hosts, which is similar to the genetic interaction that has been demonstrated for rust, Melampsora lini on varieties of flax, Linum usitatissimum. ${ }^{11}$

According to this concept, for every major gene for resistance in the host species there is a corresponding matching gene for virulence in the parasite. The host plant shows a resistant reaction when it has a resistance gene and the insect has an avirulent allele at the corresponding gene locus. On the other hand, the plant is susceptible when the insect has a virulent gene at the corresponding locus. The gene-for-gene relationship has been called the 'matching gene theory'. ${ }^{25}$. According to this concept, a Hessian fly biotype can be virulent to a specific wheat cultivar, only when the biotype is homozygous for a recessive virulent gene at all loci corresponding to the loci at which the wheat plant has dominant alleles for resistance ${ }^{12}$ (Table 2). For example, the wheat cultivar 'Turkey' is susceptible to all Hessian fly biotypes because it has no genes for resistance. The wheat cultivars 'Seneca', 'Monon', 'Knox 62' and 'Abe' are resistant to the GP biotype because GP has no genes 
Table 2. Genotypes of eight selected Hessian fly biotypes (after Gallun)

\begin{tabular}{|c|c|c|c|c|c|}
\hline \multirow{3}{*}{ Biotype } & \multicolumn{5}{|c|}{ Wheat Varieties $^{\mathrm{a}}$} \\
\hline & Turkey. & Seneca & Monon & Knox -62 & Abe \\
\hline & & $\mathrm{H}_{7} \mathrm{H}_{8}$ & $\mathrm{H}_{3}$ & $\mathrm{H}_{6}$ & $\mathrm{H}_{5}$ \\
\hline GP & tt & $\mathrm{S}_{-}$ & $M_{-}$ & $\mathrm{K}_{-}$ & $\mathrm{A}_{-}$ \\
\hline A & $\mathrm{tt}$ & ss & $M$ & $\mathbf{K}_{-}$ & $\mathrm{A}$ \\
\hline B & tt & ss & $\mathrm{mm}$ & $\mathbf{K}_{-}$ & $\mathrm{A}_{-}$ \\
\hline C & $t t$ & ss & $\mathrm{M}_{-}$ & $\mathrm{kk}$ & $A_{-}$ \\
\hline D & tt & ss & $\mathrm{mm}$ & kk & $A_{-}$ \\
\hline $\mathrm{E}$ & $t t$ & $\mathrm{~S}_{-}$ & $\mathrm{mm}$ & $\mathrm{K}_{-}$ & $A_{-}$ \\
\hline $\mathrm{F}$ & $t t$ & $\mathrm{~S}_{-}$ & $\mathrm{mm}$ & $\mathrm{kk}$ & $A_{-}$ \\
\hline G & $\mathrm{tt}$ & $S_{-}$ & $\mathrm{mm}$ & $\mathrm{kk}$ & A_ \\
\hline
\end{tabular}

a: Symbols designate recessive and dominant alleles that represent virulence in the insect and susceptibility in the plant; and avirulence in the insect and resistance in the plant, respectively (see the section on the gene-for-gene theory in the text for a detailed explanation).

for virulence to these resistant wheats. The wheat cultivars Seneca, Monon, Knox -62 and Abe are susceptible to biotype $L$ because this biotype has recessive alleles for virulence at the loci corresponding to the resistance alleles in the wheat. Therefore, when a biotype has homozygous recessive alleles at a locus, then it is virulent on a wheat that has at least one dominant allele at the corresponding locus for resistance. For example, biotypes $\mathrm{A}$ through $\mathrm{D}$, with homozygous recessive alleles at the $\mathrm{H}_{7} \mathrm{H}_{8}$ locus of Seneca, are virulent.

\subsection{Genetics of virulence}

Hybridization experiments on different biotypes have shown that virulence in the fly is controlled by recessive genes. ${ }^{15,19}$ Also, the virulent genes at different loci are not alleles of the same gene. ${ }^{13}$ Gallun and Hatchett ${ }^{15}$ and Hatchett and Gallun 19 showed that the segregation ratio of reciprocal crosses of Hessian fly biotypes depended on heterozygosity and the direction of the mating. The heterozygous male bred as if they were homozygous. The differences in virulence observed in these reciprocal crosses were explained on the basis of the loss of the paternally derived chromosomes containing the virulent genes in the male. Metcalfe ${ }^{26}$ studied the germ cell cycle of the 
Hessian fly and observed that during spermatogenesis the reduction of $2 \mathrm{n}=16$ chromosome to $\mathrm{n}=8$ chromosome is accomplished by two unequal divisions. In each division, four chromosomes are expelled in bud-like processes from the main cell, so that only one functional spermatid remains and the haploid set has then eight chromosomes.

\section{Evolution of Biotypes}

The formation of new biotypes in the Hessian fly accelerates in response to the wide scale use of wheat cultivars with specific genes for resistance. This is related to changes in the gene frequencies that determine virulence in the insect. According to Mackenzie ${ }^{24}$ a stable equilibrium of the gene frequency results from several reasons. The first reason is known as the Hardy-Weinberg law. This law states that unless acted upon by some outside force, gene frequencies will remain unchanged from generation to generation. Outside forces which might upset this equilibrium are nonrandom mating, differential mutation rates between alleles, migration or selection. A second case for genetic equilibrium could result from stabilizing selection. ${ }^{10}$ This stabilizing process operates against the extreme classes and maintain the mean, reducing the variance. A third cause of genetic equilibrium is balanced polymorphism. Heterozygote advantage in diploids is one of the ways in which balanced polymorphism is maintained. The heterozygotes (Aa) of one generation produce less fit homozygotes (AA and aa) in the next generation.

Selection intensity expressed by widespread use of a resistant cultivar results in biotypes that can live on these cultivars. Selection proceeds, when possible, in the direction of increased fitness in the pest population. This effect is called the directional selection. The directional selection for parasitic fitness could operate only in those populations with some genetically different types. Genetic variance is' necessary for the selection to proceed. The variance could come from several sources, mutation and sexual recombination being two very important and obvious sources.

Since avirulence in the Hessian fly is determined by dominant genes, mutation into recessive alleles could bring about changes in virulence. The most important source of genetic variance in Hessian fly populations is provided, however, by genetic recombination. For instance, a mating between two flies of biotype A with the genotypes ssMmKK (loci for Seneca, Monon and Knox 62) and ssMmKk would result in two other genotypes, ssMMKK and ssmMkk, taking into consideration the fact that only maternally derived chromosomes in the male are transmitted into the progeny. ${ }^{14}$ If a female of genotype ssmMKK mates with a male fly having the same genotype, then two kinds of genotypes are produced: ssmmKK (biotype B) and ssMmKK (biotype A). If no selection pressure is exerted against this population, biotype $B$ genotypes would remain in the population 
and be diluted with avirulent biotype A flies. However, if wheat having genes for resistance to biotype $A$ is cultivated, then selection operates against this biotype, with a corresponding increase of biotype $B$.

This is apparently what has happened in Indiana and in adjoining states where similar wheats were grown. Biotype A occurred when flies having double recessive alleles at the Seneca or S locus appeared in the population due to the selection pressure of Seneca wheat or wheats with similar resistance. This left biotype $\mathrm{A}$ in the field because there was no selection pressure by any other kind of wheat resistance. When Monon wheat and other cultivars of the same genetic resistance were used widely, biotype B became prevalent. ${ }^{19}$ To combat this new biotype, cultivars having the $\mathrm{H}_{6}$ gene resistant to biotype A and B were developed. ${ }^{1}$ This resulted in the development of biotypes like $\mathrm{C}$ and $\mathrm{D}$, which can survive on wheats with the $\mathrm{H}_{6}$ gene of resistance. The $\mathrm{H}_{5}$ gene, ${ }^{36}$ derived from the Portuguese wheat 'Ribeiro' has been utilized extensively in the Purdue University-U.S. Department of Agriculture wheat breeding program, and is present in wheat cultivars A'be and Arthur $71 . .^{33}$ Following the cultivation of these varieties, biotypes $\mathrm{J}$ and $\mathrm{L}$ appeared in the field. ${ }^{37}$

\section{Management of Resistance}

The present method of deploying Hessian fly resistant genes in most wheat breeding programs is to incorporate a single gene into cultivars and use it until the resistance it provides is no longer effective. When a virulent fly biotype has rendered the currently deployed gene(s) ineffective, new genes are crossed to elite breeding lines and subsequently utilized in the breeding program. This method, however, can eventually use all the available genes for resistance. Therefore, a rational approach of utilizing valuable genes that will afford protection to wheat over the maximum number of years is necessary.

The management of resistant genes to maximize the durability has been discussed in plant pathology literature. Browning et al. ${ }^{3}$ advocated incorporating genes of major effect into multiline cultivars. These multilines consist of several components, each having a single resistant gene. In contrast, Nelson ${ }^{27}$ suggested the accumulation of as many resistant genes as possible into individual cultivars (Pyramiding), in order to provide a cumulative effect.

Recently, Cox and Hatchett ${ }^{7}$. have described a rational approach for the deployment of resistant genes against Hessian fly. According to their genetic model, deployment of eight resistant genes in a single cultivar would result in a rapid loss of protection since each allele applies a heavy selection pressure, and the insect loci evolve independently. Dispersed, simultaneous 
deployment in eight different cultivars or isolines would afford protection over 45 years because of the reduced selection pressure exerted by each resistant allele. In this strategy, resistant alleles could be used sequentially, by phasing in each in $25 \%$ yearly increments while phasing out the previous allele, then utilizing the new allele exclusively for four years before beginning to phase out. This strategy would supposedly provide more durability than does the dispersed simultaneous deployment.

Gould $^{18}$ proposes a different strategy of deploying resistant genes for the control of the Hessian fly. He proposes that mixing $20 \%$ susceptible seed with $80 \%$ single factor resistant wheat could extend the durability of the sequentially released germplasm. Also, when the antibiotic effects of the resistant factors are high, pyramiding two genes into a single cultivar increases productive life of the variety than does the single gene resistance. The productive life can be further increased by using a cultivar with two genes for resistance interplanted with a susceptible cultivar.

Some problems in implementing resistant germplasm deployment strategies are obvious. For example, it is more difficult to breed and register a pyramided cultivar than does a pure cultivar. The interplanting of a susceptible cultivar with a resistant cultivar can be difficult because farmers may prefer to use a single cultivar. This strategy will demand a more efficient seed production process than does the use of a pure cultivar.

\section{Application to rice breeding programs in Sri Lanka}

In Sri Lanka several pest resistant high yielding rice varieties have been developed and widely used by farmers. ${ }^{35}$ Among these varieties ' $\mathrm{Bg} 400-1$ ', 'Bg 276-5' are resistant to the rice gall-midge, Orseolia oryzae (Wood Mason) and ' $\mathrm{Bg} \cdot 379-2$ ' is resistant to the rice brown planthopper, Nilaparvata lugens (Stal).

Adaptation of rice pests, particularly the brown planthopper to resistant varieties of rice has been shown to occur both in the laboratory and in the field. 6,22

Genetic interaction between rice pests like the brown planthopper and resistant varieties is not well understood and far from being conclusive. 8 However, studies by Barrion and Saxena ${ }^{2}$ suggested a gene-for-gene relationship between host varietal resistance and virulence of three biotypes of the brown planthopper. This type of interaction is similar to the one discussed for host resistance in wheat and virulence of different biotypes of the Hessian fly. 
The ability of the rice pests to adapt to resistant varieties is most probable; therefore host plant resistance will continue to provide an inexpensive and reliable form of pest control for the Sri Lanka farmer.

Identification of diverse and different sources of resistance for rice pests as accomplished in the Hessian fly-wheat resistant breeding program will likely be the cornerstone of a successful breeding program. Concurrent to the identification of diverse sources of resistance to a particular biotype of an insect pest, the genetic diversity in that pest should be surveyed. The principles used in the identification of biotypes of the Hessian fly should have direct application in the identification of biotypes of the rice gallmidge, which also belongs to the same family Cecidomyiidae.

In a program to develop insect-resistant rice cultivars, consideration should be given to strategies of deploying the resistance in a way that will delay the rate of evolution of biotypes. The sequential release of cultivars with major genes for resistance can play a major role in the pest resistant breeding program in Sri Lanka. The incorporation of major genes for resistance in a high yielding variety is relatively simple. Farmers in Sri Lanka use different age class cultivars according to the season, availability of water and personal preference. When different genes for resistance are used in rice cultivars of different age classes, the adaptation of the pests on these cultivars should be slower than if all these varieties had the same genes for resistance.

Pyramiding several major genes for resistance in the same improved cultivar is another strategy to manage biotype development as discussed earlier for the Hessian fly. Plant varieties with several major genes for resistance are subject to less selection pressure and therefore have more durable resistance than varieties with single genes.

\section{Conclusions}

The knowledge obtained from the development of biotypes of the Hessian fly and the selection and breeding of wheats that are resistant to the insect can be applied to the selection of rice cultivars resistant to certain insect pests. The success of a pest resistance breeding program on rice will depend on the continous search for new sources of resistance in the crop, the incorporation of resistance genes into high yielding varieties and the planned use of these varieties in a way that will limit biotype development. Closeco-operation between entomologists and plant breeders is a pre-requisite for success in breeding for insect resistance. 


\section{References}

1. AllAN, R.E., HEYNE, E.G., JONES, E.T. \& JENSON, C.O. (1959). Genetic analysis of ten sources of Hessian fly resistance, their interrelationships and association with leaf rust reaction in wheat. Kansas. Agr. Exp. Stn. Tech. Bull., No. 104. 51 pp.

2. BARRION, A.A. \& SAXENA, R.C. (1984). Genetics of virulence in three biotypes of brown planthopper, Nilaparvata lugens (Stal). Paper presented at the Department of Entomology Seminar, International Rice Research Institute, Los Banos, Laguna, Philippines.

3. BROWNING, J.A., SIMONS, M.D. \& TORRES, E. (1977). Managing the host genes: epidemiological and genetic concepts. Plant Disease, 1: 191-211.

4. CALDWELL, R.M., CARTWRIGHT, W.B. \& COMPTON, L.E. (1946). Inheritance of Hessian fly resistance derived from the W38 and Durum P.I. 94587. J. Am. Soc. Agron., 38: 398-409.

5. CLARIDGE, M.F. \& DEN HOLLANDER, J. (1983). The biotype concept and its application to insect pests of agriculture. Crop Protection, 2: 85-95.

6. CLARIDGE, M.F., DEN HOLLANDER, J. \& FURET, I. (1982). Adaptation of brown planthopper (Nilaparvata lugens) Populations to rice varieties in Sri Lanka. Ent. Exp. \& Appl., 32: 222-226.

7. COX, T.S. \& HATCHETT, J.H. (1986). Genetic model for wheat/Hessian fly interaction: 'Strategies for' deployment of resistant genes in wheat cultivars. Environ. Entomol., 15 : 24-31.

8. DEN HOLLANDER J. \& PATHAK, P.K. (1981). The genetics of the 'biotypes' of rice brown plant hopper, Nilaparvata lugens (Stal). Ent. Exp. Appl. 29: 76-86.

9. DIEHL, S.R. \& BUSH, G.L. (1984). An evolutionary and applied perspective of insect biotypes. Ann. Rev. Entomol., 29: 471-504.

10. FALCONER, D.S. (1981). Introduction to quantitative genetics. Longman, New York. $340 \mathrm{pp}$.

11. FLOR, H.H. (1956). The complementary genetic system in flax and flax rust, Adv. Gen., 8: 29-54.

12. GALLUN, R.L. (1977). Genetic basis of Hessian fly epidemics. Ann. N.Y. Acad. Sci., 207 : 223-229. 
13. GALLUN, R.L. (1978). Genetics of the biotypes $B$ and C of Hessian fly. Ann. Entomol. Soc. Amer. 70: 481-486.

14. GALLUN, R.L. (1983). Genetics of host parasite interaction in Hessian fly, Mayetiola destructor (Say), and wheat. In, Genetics: New Frontiers. Proc. XV Int. Congress of Genetics, New Delhi, India; Dec. 12-21, 1983.

15. GALLUN, R.L. \& HATCHETT, J.H. (1968). Interrelationship between races of Hessian fly, Mayetiola destructor (Say) and resistance in wheat. In, Proc. $3 r d$ Int. Wheat Genetics Symp. (Aust. Acad. Sci., Canberra) : 258-262.

16. GALLUN, R.L. \& PATTERSON, F.L. (1977). Monosomic analysis of wheat for resistance to Hessian fly. J. Hered. 68: 223-226.

17. GILL, B.S., HATCHETT, J.H. \& RAUPP, W.J. (1987). Chromosomal mapping of Hessian fly-resistant gene $\mathrm{H}_{13}$ in the D genome of wheat. J. Hered., 78: 97-100.

18. GOULD, F. (1986). Simulation models for predicting durability of insect-resistant germ plasm: Hessian fly (Diptera; Cecidomyiidae)-resistant winter wheat. Environ.Entomol. 15: 11-23.

19. HATCHETT, J.H. \& GALLUN, R.L. (1970). Genetics of the ability of the Hessian fly, Mayetiola destructor (Say), to survive on wheat having different genes of resistance. Ann. Entomol. Soc. Amer. 63: 1400-1407.

20. HATCHETT, J.H. \& G.ILL, B.S. (1981). D-Genome sources of resistance in Triticum tauschii to Hessian fly. J. Hered. 72: 126-127.

21. KUDAGAMAGE, C. (1987). Biotypes of Hessian fly, Mayetiola destructor (Say) in the southeastern United States and genetic interactions of Hessian fly biotypes $M$ and $L$ with wheat cultivar Abe. Ph.D. Thesis, Purdue Univ., W. Lafayette, Indiana. $106 \mathrm{pp}$.

22. KUDAGAMAGE, C. \& NUGALIYADDA, L. (1984). Development of new biotypes of brown plant hopper on Bg 379-2, a resistant variety. Proc. First Arnual Research Conference of the Research Division of the Department of Agriculture held in the Inservice Agriculture Training Center, Gannoruwa, Peradeniya, Sri Lanka.

23. MAAS III, F.B., PATTERSON, F.L., FOSTER, J.E. \& OHM, H.W. (1987). Expression and inheritance of resistance of ELS 6404-160 durum wheat to Hessian fly. Crop Sci. (in press).

24. MACKENZIE, D.R. (1980). The problem of variable pests. In F.G. Maxwell \& P.R. Jennings (eds), Breeding Plants Resistant to Insects. John Wiley \& Sons, New York. 683 pp. 
25. MAXWELL, F.G. \& JENNINGS, P.R. (1980). Breeding Plants Resistant to Insects. John Wiley \& Sons, New York. 683 pp.

26. METCALFE, M.E. (1935). The germ cell cycle in Pbytopbaga destructor (Say). Quart. J. Micros. Sci. 77:585-606.

27. NELSON, R.R. (1978). Genetics of horizontal resistance to plant diseases. Ann. Rev. Phytopatbol. 16: 359-378.

28. NOBLE, W.B. \& SUNESON, C.A. (1943). Differentiation of two genetic factors for resistance to Hessian fly in 'Dawson' wheat. J. Agric. Res. 76: 27-32.

29. OELLERMAN, C.M., PATTERSON, F.L. \& GAllun, R.L. (1983). Inheritance of resistance in 'Luso' wheat to Hessian fly. Crop. Sci. 23: 221-224.

30. PATTERSON, F.L.; FOSTER, J.E. \& OHM, H.W. (1987). Gene $\mathrm{H}_{16}$ for resistance to Hessian fly. Crop Sci. (in press).

31. PATTERSON, F.L. \& GALLUN, R.L. (1984a). Inheritance of resistance of Seneca wheat to race E of Hessian fly. P 445-449. In, E.R. Sears \& L.M.S. Sears (eds.), Proc. 4th Int. Wheat Genet. Symp., Columbia, Missouri.

32. PATTERSON, F.L. and Gallun, R.L. (1984b). Linkage in wheat of the $\mathrm{H}_{3}$ and $\mathrm{H}_{6}$ genetic factors for resistance to Hessian fly. J. Hered. 68: 293-296.

33. PATTERSON, F.L., GALLUN, R.L., ROBERTS, J.J., FINNEY, R.E. \& SHANER, G.E. (1975). Registration of Arthur 71 and Abe wheat. Crop Sci. 15: 736.

34. ROBERTS, J.J. \& GALLUN, R.L. (1984). Chromosome location of $\mathrm{H}_{5}$ gene for resistance to Hessian fly in wheat. J. Hered. 75 : 147 -148.

35. SENADHIRA, D., KUDAGAMAGE, C. \& PERIS, P.E. (1981). New rice varieties of Sri Lanka. Int. Rice Comm. Newsletter; 30: 19-20.

36. SHANDS, R.G. \& CARTWRIGHT, W.B. (1953). A fifth gene conditioning Hessian fly responses in common wheat. Agron. J. 45: 302-307.

37. SOSA JR., O. (1981). Biotype $\mathrm{J}$ and $\mathrm{L}$ of Hessian fly, discovered in an Indiana wheat field. J. Econ. Entomol. 74: 180-182.

38. STEBbinS, N.B., PATTERSON, F.L. \& GALlUN, R.L. (1982). Interrelationships among wheat genes $\mathrm{H}_{3}, \mathrm{H}_{6}, \mathrm{H}_{9}$ and $\mathrm{H}_{10}$ for resistance to Hessian fly. Crop. Sci. 22: 1029-1032.

39. SUNESON, C.A. \& NOBLE, W.B. (1950). Further differentiation of genetic factors in wheat for resistance to Hessian fly. U.S. Dept. Agric. Tech, Bull. No. $104.8 \mathrm{pp}$. 